\title{
Study on the Catalytic Effect of Nitric Acid Activated Myanmar Natural Clay for the Degradation of Plastic Wastes
}

\author{
Amie Thant, Chaw Su Su Hmwe
}

\begin{abstract}
In this study, the performance of different acid treated Myanmar Natural Clay (Mabisian) was conducted the pyrolysis of mixed plastic wastes, $40 \%$ high density polyethylene, $30 \%$ polypropylene, $25 \%$ low density polyethylene and $5 \%$ polystyrene. Mabisian clay was refluxed with different concentration of nitric acid $(2 \mathrm{M}, 4 \mathrm{M}, 6 \mathrm{M}, 8 \mathrm{M}$, $10 \mathrm{M}, 12 \mathrm{M}$ and $14 \mathrm{M}$ ) at $100^{\circ} \mathrm{C}$ for $3 \mathrm{hrs}$ followed by calcination at $500^{\circ} \mathrm{C}$ for $1 \mathrm{hr}$. The physico-chemical characteristics of resulted leached clay were studied by X-Ray Fluoresence spectroscopy (XRF), X-Ray Diffraction (XRD) and Fourier Transformed Infrared Spectroscopy (FTIR). The pyrolytic oil was characterized by Gas Chromatography - mass spectopy (GC-MS). XRF and FTIR studies indicated that acid treatment under reflux condition lead to the removal of octahedral $\mathrm{Al}^{3+}$ cations along with other impurities. The chemical treatment increased the $\mathrm{Si} / \mathrm{Al}$ ratio. The maximum liquid yield $(75 \%)$ was obtained at $12 \mathrm{M}$ nitric acid, $3 \mathrm{hr}$ reaction time and $100^{\circ} \mathrm{C}$ reaction temperatures. In addition, the percent peak area of gasoline range hydrocarbon was obtained $55.6 \%$ at optimum condition. Thus, the treated clay can be used as promising as catalyst support.
\end{abstract}

Index Terms-Acid Activation; Mabisian Clay; Nitric Acid; Pyrolysis; Plastic Wastes; Physico-Chemical Character; Catalyst Support.

\section{INTRODUCTION}

Nowadays, the industrialization and population was growing. It makes the problem for disposing the solid waste around the world. The more the world population rapidly grows the more consumption of the plastics increase. Plastics materials are utilized from domestic appliances to agricultural because of their effective ways such as light weight characteristics, high chemical stability and low degradability.

Plastic wastes can be turned into valuable energy since they are derived from petrochemical source which having significant calorific value. Municipal and industrial wastes are disposed by landfilling, incineration, true material recycling, and chemical recovery. The emission of air bone particles and carbon dioxide into the atmosphere can cause the dangerous air pollution problems by landfill treatment and incineration [1].

Chemical recycling is more suitable than any other materials recycling method around the world. Pyrolysis

Published on August 31, 2018.

A. Thant is a lecturer at Mandalay Technological University, Mandalay, Myanmar. She completed her BE at Technological University, Mandalay and M.E at De La Salle University, Manila, Philippines. (e-mail: amythant81@gmail.com).

C. S. S. Hmwe is a Professor at Mandalay Technological University, Mandalay, Myanmar. She completed her $\mathrm{BE}$ and $\mathrm{PhD}$ at the same University and she completed her ME at Yangon Technological University, Yangon, Myanmar (e-mail: chawsu2hmwe@gmail.com). means thermal cracking of high molecular weight hydrocarbon turns into low molecular weight hydrocarbon under absent of oxygen atmosphere. The three major products of pyrolysis process are oil, gas and char. The liquid product can be used in furnace, boiler, turbine and diesel engines without upgrading or treatment [2],[3].

In the study of catalytic cracking and thermal cracking, the catalyst cost is found as an important factor. The thermal cracking requires the high temperature and longer reaction time and produces the higher molecular chain while the catalytic cracking can reduce the reaction temperature and reaction time [4]. In cracking of plastic wastes, natural and synthesis catalyst can be utilized. Natural catalysts are cheaper than synthesis catalysts.

Ferric carbonate catalyst and waste plastic mixture to fuel production reports showed that higher percentage catalyst adding fuel conversion rate is increasing. High percentage catalyst added increased the light gas production percentage and produced light gas can be used for heat source when large scale production starts. However, high percentage catalyst added to fuel production cost will be increase because catalyst has to buy from market and it adding extra cost also during production period [5].

The use of clay-type aluminosilicates in heterogeneous catalysis as solid acid catalysts is almost as old as the catalysis concept itself. In modern petrochemical processes, the zeolite acid catalyst is employed. However, acid modified clays are more attractive due to their low cost and their suitable pore structure than zeolite for the degradation of long chain molecules [6].

Although it has a very low catalyze ability reaction in natural clay, various activation methods can change the structural properties of natural clay to generate catalysts with high acidity, surface area, porosity and thermal stability. [7]. Acid modification is widely accepted as an effective method to create active materials for adsotption and catalysis purposes. The increasement of $\mathrm{Si} / \mathrm{Al}$ ratio will improve not only the stability of the crystal framework but also reduce the coke formation during the catalytic cracking [8].

The study on the effect of sulphuric acid treatment on the physico-chemical characteristics of kaolin clay under refluxed condition has been concluded that sulphuric acid treatment at and above $5 \mathrm{M}$ concentration almost destroys the crystalline structure and other properties to a considerable extent [9].

The present work studied the effect of nitric acid treated Myanmar natural clay on distribution of liquid hydrocarbon products. 


\section{MATERIAL AND EXPERIMENTAL}

\section{A. Materials}

In this study, Myanmar Natural Clay (Mabisian) was used as a catalyst support. It was collected from Department of Research and Innovation. Raw materials used for this study are mixed plastic wastes (High density polyethylene, Low density polyethylene, Polypropylene and Polystyrene) natural catalysts and starch powder. Plastics wastes were cut into smaller sizes $(6 \mathrm{~mm} \times 6 \mathrm{~mm})$. All chemicals used were analytical reagent grade, obtained from Able Chemical, Mandalay.

\section{B. Acid Modification}

The experimental set-up for the acid activation process was shown in Fig. 1. The acid activation was carried out by adding $30 \mathrm{~g}$ of the clay put into $500 \mathrm{ml}$ of two- neck flat bottom flask. And then $300 \mathrm{ml}$ of various concentration of nitric acid solution $(2 \mathrm{M}, 4 \mathrm{M}, 6 \mathrm{M}, 8 \mathrm{M}, 10 \mathrm{M}, 12 \mathrm{M}$ and 14 M) was poured into the reactor equipped with a reflux condenser under stirring condition at $100^{\circ} \mathrm{C}$ for $3 \mathrm{hr}$. The resulting clay suspension was then rapidly quenched by adding $500 \mathrm{ml}$ of ice cold water. The slurry was washed repeatedly with distilled water until neutral point was obtained. The washed clay was dried in an oven. After that the dried clay was calcined at $500^{\circ} \mathrm{C}$ for $2 \mathrm{hr}$ and ground in a mortar and pestle to get powder form. The untreated sample is referred to as $\mathrm{NH}$ and treated samples are referred to as $\mathrm{NH} 1, \mathrm{NH} 2, \mathrm{NH} 3, \mathrm{NH} 4, \mathrm{NH} 5, \mathrm{NH} 6$ and $\mathrm{NH} 7$ in the subsequent text where the numbers refer to the different concentration of acid used.

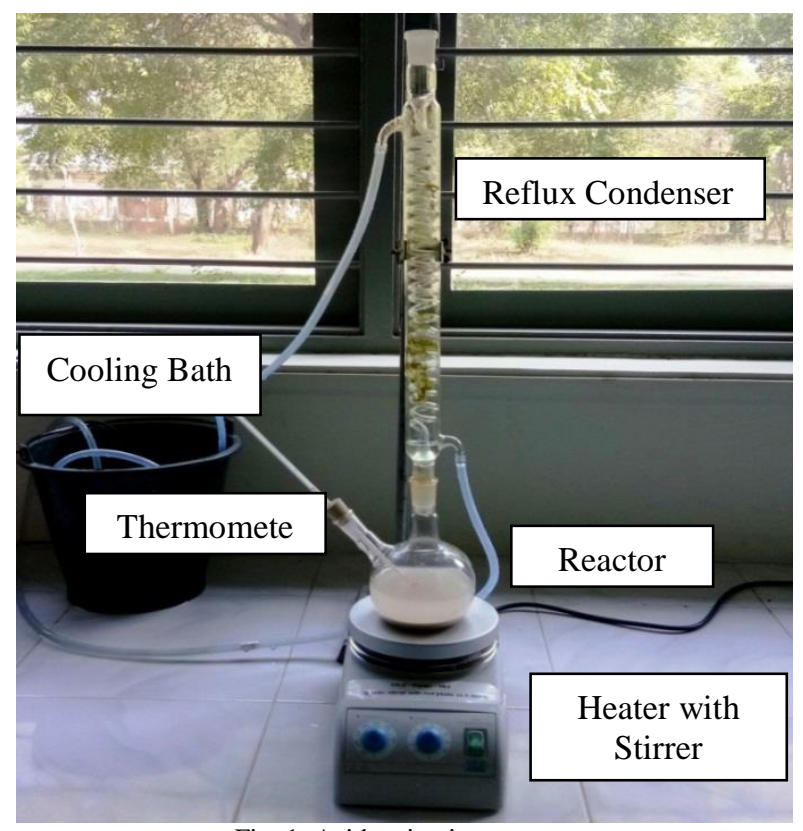

Fig. 1. Acid activation process

\section{Pyrolysis of Mixed Plastic Wastes}

The experimental set-up for pyrolysis process was shown in Fig. 2. The experiment was carried out by loading $200 \mathrm{~g}$ of mixed plastic wastes such as $40 \%$ HDPE, $30 \%$ PP, $25 \%$ LDPE and 5\% PS into the fixed bed reactor and $20 \mathrm{~g}$ of catalyst into the catalyst bed. Before starting experiment, nitrogen was flowed to the reactor to wash out oxygen from the reaction medium. In the catalytic pyrolysis process, two- staged condenser was used. The inlet and outlet temperature of hot water from $95^{\circ} \mathrm{C}$ to $70^{\circ} \mathrm{C}$ for the first stage condenser while The inlet and outlet temperature of cold water in shell side were $10{ }^{\circ} \mathrm{C}$ and $27{ }^{\circ} \mathrm{C}$ for second stage condenser. The reactor was heated with an electric furnace at a rate of $5^{\circ} \mathrm{C}$ min-1 to reach the desired temperature. The reactor temperature was controlled and monitored by a set of temperature controller and thermocouple. The temperature range was maintained at from $200^{\circ} \mathrm{C}$ to $400^{\circ} \mathrm{C}$. Crude liquid fuel and waxes flowed into the collector and the light gases were stored by the gas bag. The liquid fuel was characterized by gas chromatography mass spectrometer (GC-MS). submission.

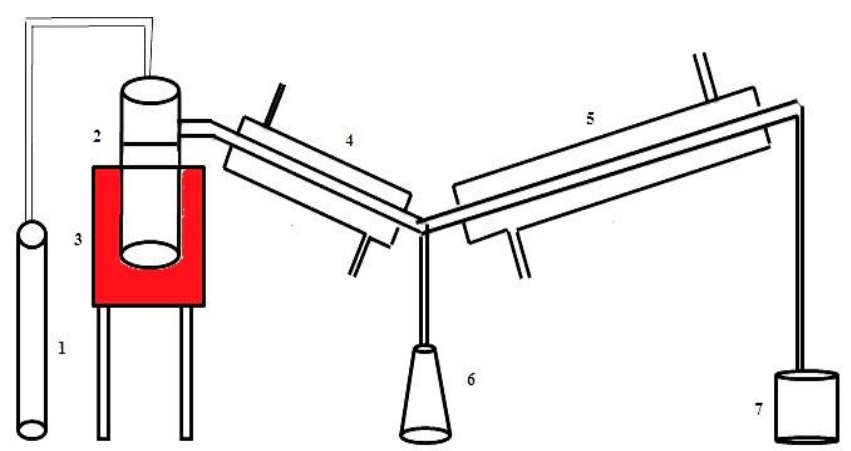

Fig. 2. Process of Catalytic Pyrolysis (1) $\mathrm{N}_{2}$, (2) thermal reactor, (3) Electronic Heater, (4) first stage condenser, (5) second-stage condenser, (6) liquid collector, (7) gas collector.

\section{Characterization Methods}

The untreated and acid treated Mabisian clay materials were characterized by X-ray fluorescence spectroscopy (XRF), X-ray diffraction (XRD) and Fourier transformed infrared spectroscopy (FTIR). The condensable gas in the form of liquid was analyzed by gas chromatography coupled with mass spectrometry detector (GC-MS). The set up parameters are given in Table I.

TABLE I: GC-MS METHOD CHARACTERISTIC

\begin{tabular}{ll}
\hline \hline Column & \\
\hline Carrier gas & $\mathrm{H}_{2}$ \\
Carrier gas flow & $1.0 \mathrm{ml} / \mathrm{min}$ \\
Initial temperature/initial time & $50^{\circ} \mathrm{C} / 2 \mathrm{~min}$ \\
Heating rate & $10^{\circ} \mathrm{C} / \mathrm{min}$ \\
Final temperature/final time & $300^{\circ} \mathrm{C} / 10 \mathrm{~min}$ \\
Injection temperature & $250^{\circ} \mathrm{C}$ \\
Injection volume & $<1.0 \mathrm{ml}$ \\
\hline \hline
\end{tabular}

XRF analyses of the samples were done using a ModelPW2400 of Phillips make, with X-ray tube of rhodium anode and scintillation detector with a current $40 \mathrm{~mA}$ and voltage $40 \mathrm{mV}$.

The X-ray diffraction data was collected using Rigaku Geigerflex RADIA, Japan, X-ray $\mathrm{Cu}$ k-ALPHa 1/40kv/25MA, scan range 0-179 deg, scan speed $4 \mathrm{deg} / \mathrm{min}$.

FTIR spectra were recorded on a Perkin-Elmer infrared spectrophotometer as $\mathrm{KBr}$ pellets with resolution of $4 \mathrm{~cm}^{-1}$, in the range of 500-4000 $\mathrm{cm}^{-1}$. 


\section{RESULT AND DISCUSSION}

\section{A. XRF Characterization}

The chemical composition changes that the effect of nitric acid treated Myanmar Natural clay was analyzed using XRF. The changes in the chemical composition of the natural and acid activated Myanmar Natural clay at different acid concentrations are shown in Table II. Si and $\mathrm{Al}$ are major components of the mabisian clay with trace amount of $\mathrm{Na}, \mathrm{Mg}, \mathrm{Ca}, \mathrm{Fe}$ and others. The $\mathrm{Si} / \mathrm{Al}$ ratio was increased as the acid concentration increased up to $12 \mathrm{M}(\mathrm{NH} 6)$ and decreased with further increase in acid concentration. The content of $\mathrm{Fe}, \mathrm{Mg}, \mathrm{Ca}, \mathrm{Na}$ in the clay decrease as an acid concentration increased while the $\mathrm{Cr}$ content did not change for any acid concentration. However, the composition of $\mathrm{Al}$ decreases up to $12 \mathrm{M}$ of acid concentration and increase with the father increase in acid concentration. The conduct showed by the $\mathrm{Al}, \mathrm{Fe}$, and $\mathrm{Mg}$ contents with progressive acid treatment is related to the progressive dissolution of the clay mineral.

TABLE II: CHEMICAL COMPOSITION OF UNTREATED AND ACID TREATED MABISIAN CLAY

\begin{tabular}{|c|c|c|c|c|c|c|c|c|}
\hline \multirow{2}{*}{$\begin{array}{l}\text { Chem } \\
\text {-ical } \\
\text { Conte } \\
\text {-nt } \\
(\mathrm{wt} \%)\end{array}$} & \multicolumn{8}{|c|}{ Materials } \\
\hline & NHO & NH1 & $\mathrm{NH} 2$ & NH3 & NH4 & NH5 & NH6 & $\mathrm{NH} 7$ \\
\hline $\mathrm{O}$ & 38.5 & 45.6 & 42.6 & 48.6 & 49.9 & 42.7 & 44.4 & 49.3 \\
\hline $\mathrm{Na}$ & 0.10 & 0.06 & 0.08 & 0.07 & 0.07 & 0.072 & 0.067 & 0.064 \\
\hline $\mathrm{Mg}$ & 0.18 & 0.13 & 0.14 & 0.13 & 0.12 & 0.13 & 0.13 & 0.13 \\
\hline $\mathrm{Al}$ & 19.7 & 18.7 & 18.7 & 18.8 & 18.7 & 18.3 & 17.7 & 18.9 \\
\hline $\mathrm{Si}$ & 27.4 & 27.7 & 27.7 & 28.5 & 29.1 & 29.1 & 29.5 & 28.1 \\
\hline $\mathrm{P}$ & 0.01 & 0.24 & 0.04 & 0.02 & - & - & 0.02 & 0.02 \\
\hline $\mathrm{S}$ & 0.01 & - & - & - & - & - & - & - \\
\hline $\mathrm{K}$ & 0.84 & 0.81 & 0.82 & 0.82 & 0.82 & 0.85 & 0.83 & 0.79 \\
\hline $\mathrm{Ca}$ & 0.02 & 0.02 & 0.01 & 0.01 & 0.01 & 0.01 & 0.01 & 0.01 \\
\hline $\mathrm{Ti}$ & 0.31 & 0.37 & 0.38 & 0.4 & 0.36 & 0.37 & 0.38 & 0.36 \\
\hline $\mathrm{Fe}$ & 1.45 & 1.36 & 1.29 & - & 1.17 & 1.22 & 1.26 & 1.24 \\
\hline $\mathrm{Cr}$ & 0.01 & 0.01 & 0.01 & 0.01 & 0.01 & 0.01 & 0.01 & 0.01 \\
\hline $\mathrm{Zr}$ & 0.01 & 0.01 & 0.01 & 0.01 & - & 0.01 & 0.01 & 0.03 \\
\hline $\mathrm{Rb}$ & 0.01 & 0.01 & 0.01 & - & 0.01 & 0.01 & 0.01 & 0.01 \\
\hline $\mathbf{S i} / \mathbf{A l}$ & 1.39 & 1.48 & 1.48 & 1.52 & 1.56 & 1.59 & 1.67 & 1.48 \\
\hline
\end{tabular}

\section{B. XRD Characterization}

X-ray diffraction method was used to study the structural changes of the untreated and acid treated Myanmar Natural Clay. The important mineralogical changes of the different concentration of nitric acid treated Myanmar Natural Clay (Mabisian) clays were shown in Fig. 3. Leaching of the Mabisian clay with nitric acid produces important mineralogical changes as seen in XRD patterns. The untreated clay shows well-defined reflections at $2 \theta$ value of $20.734^{\circ}, 24.815^{\circ}$, and $26.538^{\circ}$ which are typical characteristic peaks of kaolinite. After the acid treatment, the intensity of the clay moderately increases up to $12 \mathrm{M}$ and decrease in further increase in acid concentration. The acid activation process can effect on the crystalinity of the Mabisian clay. The increase of crystallite size depends on the intensity increase while the decreases of the mean lattic strain.

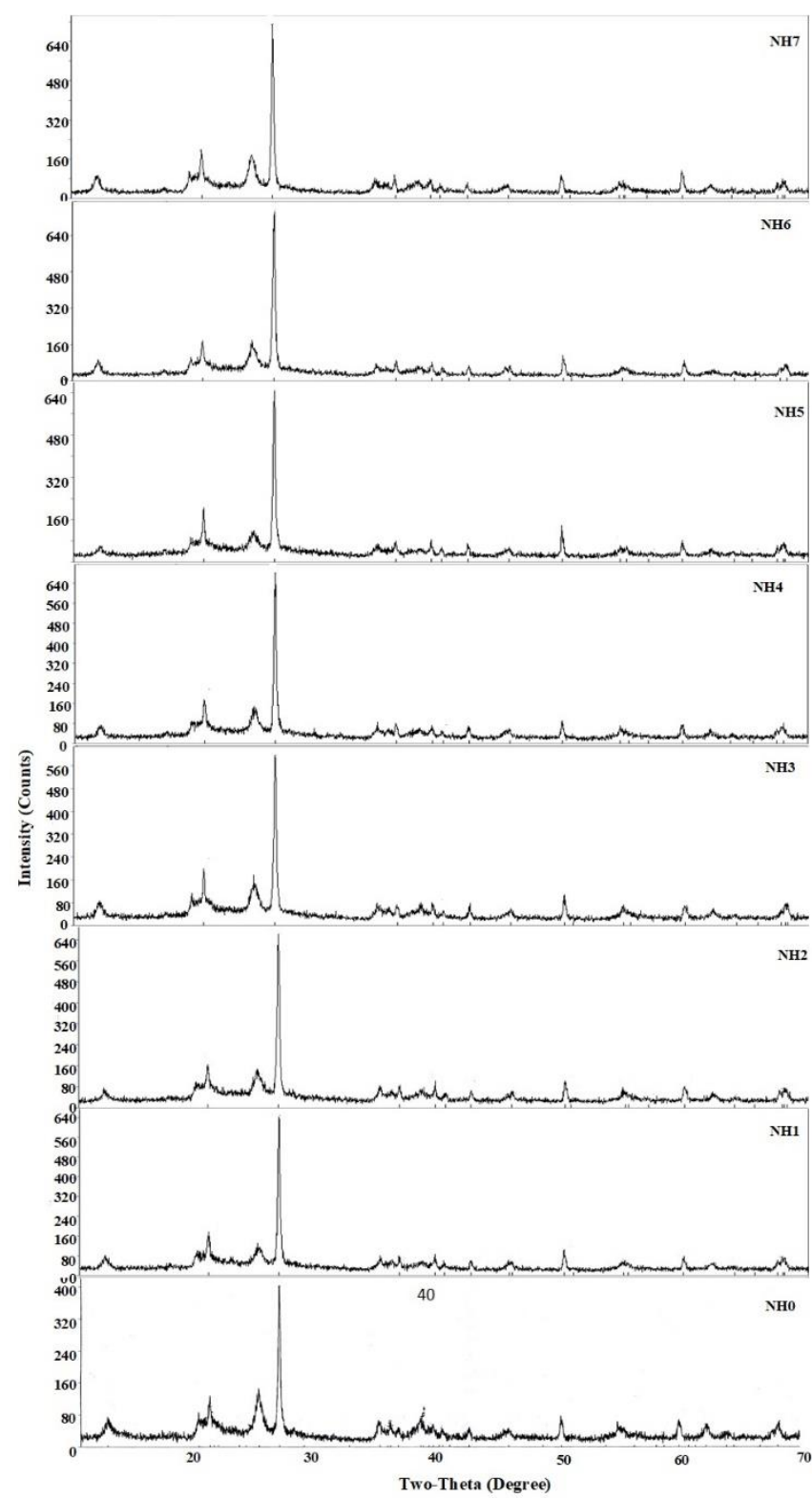

Fig. 3. X-ray diffraction patterns of the natural and acid-treated Mabisian Clay

\section{FTIR Characterization}

In order to study the effect of acid -leaching on the mabisian clay, FTIR analysis technique was used in the range from $500-4000 \mathrm{~cm}^{-1}$. The FTIR spetra of the raw and acid leached samples are shown in Fig. 4. This indicates that the functional groups change during the acid activation process. During the acid-leaching of the clay samples the cations from the acid medium penetrate into the clay structures attacking the $\mathrm{OH}$ groups thereby causing the alteration in the adsorption bands attributed to the $\mathrm{OH}$ vibrations and octahedral cations. The untreated sample shows absorption band 547.8, 695.36, 796.63, 911.4, $1002.05,1051.24,1114.89,3457.52,3620.51,3696.7 \mathrm{~cm}^{-1}$. In the $\mathrm{O}-\mathrm{H}$ stretching region, the parent and acid treated clay show two prominent bands at $3620.51,3693.7 \mathrm{~cm}^{-1}$ corresponds to Al-OH stretching]. The intensity of absorption band was decrease at $3620 \mathrm{~cm}^{-1}$ after acid activation. It is due to the removal of octahedral cations, causing the loss of water. The band at 1114.89, 1051 and $1002.05 \mathrm{~cm}^{-1}$ disappeared after the acid treatment of the clay sample. Again, strong bands are found in the $908-916 \mathrm{~cm}^{-1}$ related to $\mathrm{Al}-\mathrm{Al}-\mathrm{OH}$ stretching and in the $795-800 \mathrm{~cm}^{-1}$ 
corresponds to $\mathrm{Al}-\mathrm{Mg}-\mathrm{OH}$ stretching in untreated and treated clay.

\section{Product Oil Yield and Oil Composition}

The catalytic cracking of mixed plastic wastes (HDPE, PP, LDPE, PS) over acid-treated Mabisian clay was studied in the fixed bed reactor. The ratio of plastic to catalyst used was 10:1. The pyrolytic product yields related to the various acid concentrations was shown in Fig. 5. A yield of liquid product increased when the acid concentration increased up to $12 \mathrm{M}$ (NH6) and decreased in further increased in acid concentration. However, the yield of oil was not significant difference on the acid concentration. In addition, the coke formation slightly decreased when acid concentration increased.

The composition of crude pyrolytic oil (liquid fuel) was characterized by using GC-MS. The quality of condensable gases (liquid fuel) derived from pyrolysis of mixed plastics waste using various concentration of nitric acid treated clay was calculated in term of gasoline range hydrocarbon. According to the GC-MS result, the composition of pyrolytic oil was influence on the various concentration of nitric acid. The relationship between the composition of the product oil and different acid concentration was shown in Fig. 6. In this figure, the range from $C_{7}-C_{12}$ indicates the gasoline range hydrocarbon and and $>\mathrm{C}_{13+}$ was describe the higher molecular weight. It can be seen that the gasoline range hydrocarbons increased with the acid concentration increased up to $12 \mathrm{M}$ of nitric acid. However, the composition of gasoline range hydrocarbons decreased with any further increase of nitric acid was used.

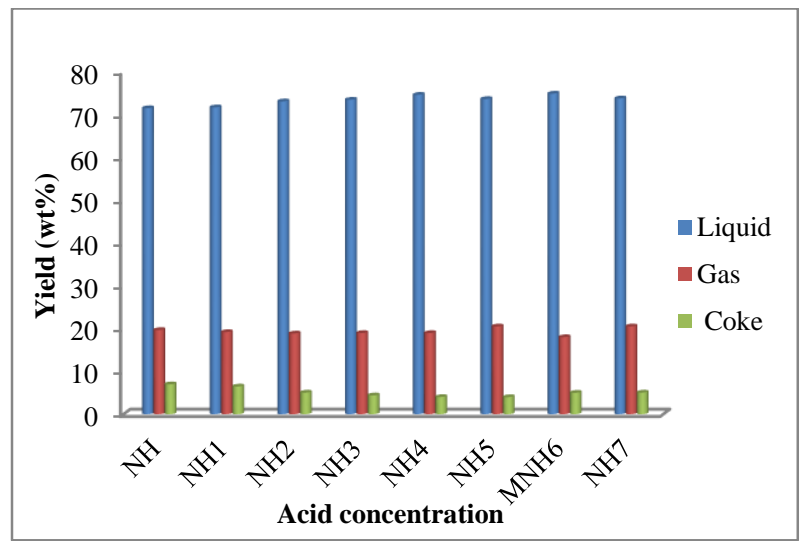

Fig. 5. Product Yield from Catalytic Pyrolysis of Mixed Plastic Wastes by using Natural and Different Acid Treated Clay as a catalyst support
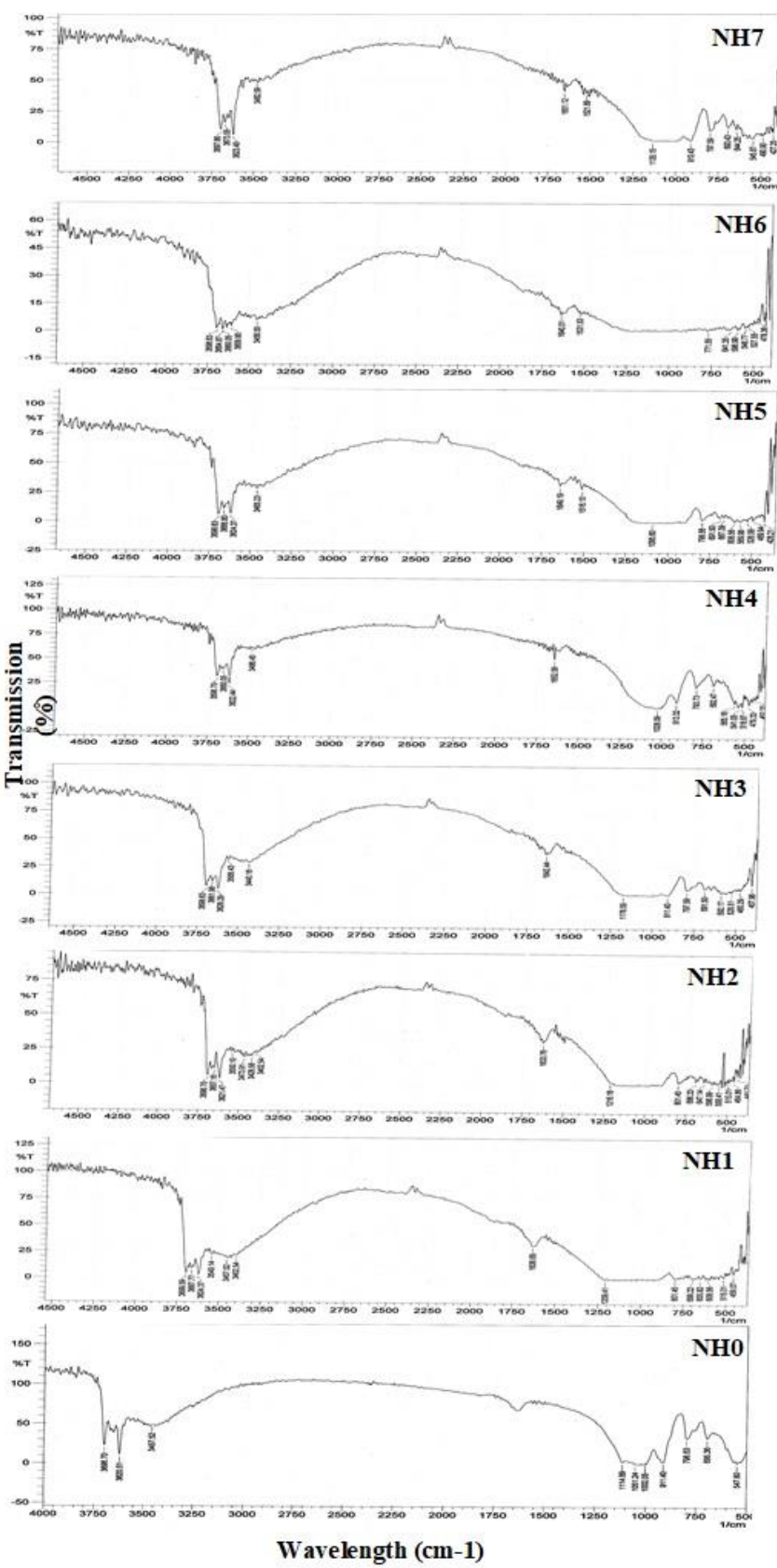

Fig. 4. FTIR Result of Untreated and Acid Treated Clay

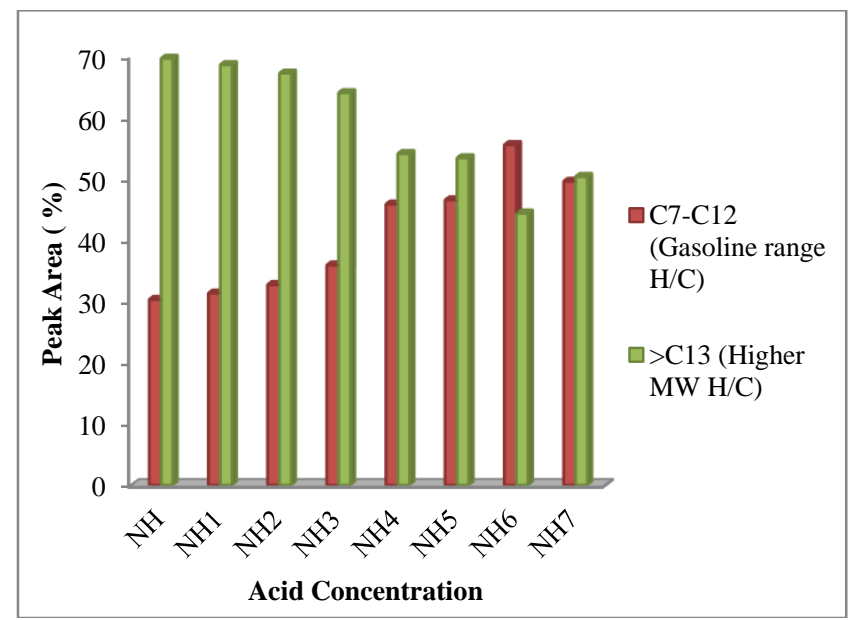

Fig. 6. Influence of Natural and Different Acid Treated Clay on the Distribution of Gasoline Range and High Molecular Weight Hydrocarbon from Catalytic Pyrolysis of Mixed Plastic Wastes. 


\section{CONCLUSION}

In this study, the catalytic degradation of mixed plastic using acid activated Mabisian clay was conducted. The XRF and FTIR study indicated that acid treatment under reflux condition lead to the removal of octahedral $\mathrm{Al}^{3+}$ cations along with other impurities. The chemical treatment increases the $\mathrm{Si} / \mathrm{Al}$ ratio from 1.39 to 1.67 . According to XRD result, the intensity of the clay moderately increases up to $12 \mathrm{M}$ and decrease in further increase in acid concentration. The FTIR results indicate that the functional groups of the Myanmar Natural Clay change during the acid activation process. The acid activation process can effect on the crystalinity of the Mabisian clay. The oil product obtained from catalytic pyrolysis of mixed plastic wastes (HDPE, LDPE, PP and PS) over acid treated clay showed only small difference in gas and oil yield in relation to the natural and different acid treated clay used. However, there was a significant difference in the composition of liquid fuel. The gasoline range hydrocarbon increased when the acid concentration increased up to $12 \mathrm{M}$ which is NH6. The catalytic cracking of mixed plastic wastes using the acid treated clay at $12 \mathrm{M}$ nitric acid, $3 \mathrm{hr}$ reaction time and $100^{\circ}$ $\mathrm{C}$ reaction temperatures as a catalyst support was given the maximum liquid yield (75\%). In addition, the percent peak area of gasoline range hydrocarbon was obtained $55.6 \%$ at optimum condition. Therefore, pyrolysis of mixed plastics waste using acid treated Myanmar Natural clay not only reduces the plastic waste problem which causes the environmental pollution but also can produce the liquid fuel. Thus, the treated clay can be used as promising as catalyst support.

\section{ACKNOWLEDGMENT}

The author wishes to express all teachers and staff, Department of Chemical Engineering, Mandalay Technological University, Myanmar for their kind help and valuable suggestions

\section{REFERENCES}

[1] Mohammad, N. S. and Halim, H. R. (2009). Catalytic coprocessing of waste plastics and petroleum residue into liquid fuel oils. Journal of Analytical and Applied Pyrolysis. Vol.86, pp.141-147.

[2] Hwang, E.Y. Kim, J.R. and Chio, J. K, (2002). Performance of acid treated natural zeolites in catalytic degradation of polypropylene. Journal of Analytical and Applied Pyrolysis. Vol.62, pp. 351-64.

[3] Rezvanipour, M, Alikhani Hesari, F. and Pazouki, M. (2014) Catalytic Pyrolysis of General Purpose Polystyrene Using Red Mud as a Catalyst. Iranian Journal of Chemical Engineering, Vol. 11, No.4, pp 10-18.

[4] Ali, S and Uemichi, Y, (2002). Polymer waste recycling over used catalysts. Catalysis Today, Vol.75, pp. 247-255.

[5] Lenarda, M. Storaro, L., Talona, A., Moretti, E., Riello, P., (2007). Solid acid catalysts from clays: preparation of mesoporous catalysts by chemical activation of metakaolin under acid conditions. Journal of Colloid Interface Sci. Vol. 311, pp. 537-543.

[6] Tae, J.W., Jang, B.S., Kin, J.R. and Park, D.W., (2004). Catalytic degradation of polystyrene using acid-treated halloysite clays. Solid State Ionics, Vol.172, pp.129-133.

[7] Syamsiro M., Cheng S. and Saptoadi H., (2014). Liquid and Gaseous fuels from Waste Plastics by Sequential Pyrolysis and Catalytic Reforming Processes over Indonesian Natural Zeolite Catalysts. Waste Technology. Vol.2, No.2, pp. 44-51.

[8] Delhez,R, Keijser, T.H., Mittemeijer, E.J., Fresenius, Z., (1982). Determination of crystallite size and lattice distortions through X-ray diffraction line profile analysis. Analytical Chemistry. Vol.312, pp. 110.

[9] Achyut P.K., Mishra, B.G., Mishra D.K., and Singh, R.K., (2010) Effect of sulphuric acid treatment on the physico-chemical characteristics of kaolin clay. Colloids and Surfaces A: Physicochem. Eng. Aspects, Vol:363, pp.98-104.

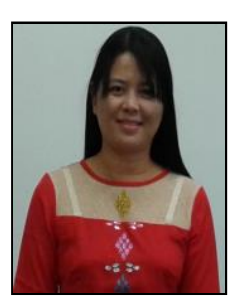

Amie Thant was born in 1983 in Myanmar. She received her BE (Chemical) from Department of Chemical Engineering, Technological University (Mandalay) Myanmar in 2005. She got her Master of Sciences in Chemical Engineering degree from De La Salle University, Manila, Philippines in 2011. Right now she is doing the research for her PhD (Thesis) in Mandalay Technological University in Myanmar.

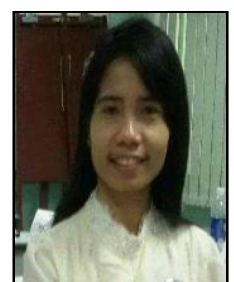

Chaw Su Su Hmwe has been working in Department of Chemical Engineering, Mandalay Technological University. She was born in 1981 in Myanmar. She received her B.E (Chemical) from Department of Chemical Engineering, Mandalay Technological University (MTU), Myanmar in 2003 She received her M.E (Chemical) from Department of Chemical Engineering, Yangon Technologica University, Myanmar in 2005. She received her PhD (Chemical) from Department of Chemical Engineering, Mandalay Technological University, Myanmar in 2011. She has been doing the research of conversion of mixed plastic wastes into liquid hydrocarbon fuel. Now she doing the research in the field of Waste Water Treatment. . 